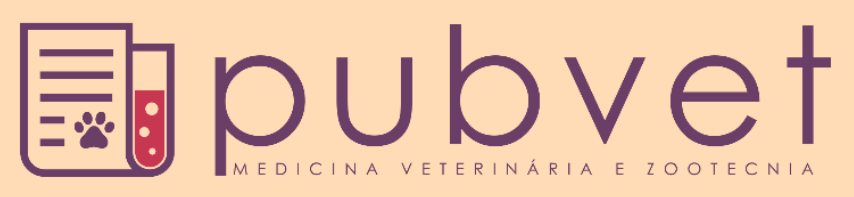

https://doi.org/10.31533/pubvet.v14n3a536.1-9

\title{
Avaliação nutricional das silagens de milho e sorgo inoculadas com Lactobacillus plantarum
}

\author{
Queila Gouveia Tavares $^{2}{ }^{\circ}$, Wellyngton Tadeu Vilela Carvalho ${ }^{3}{ }^{\circ}$, Renata Vitarele Gimenes \\ Pereira $^{3}{ }^{\circ}$, Duarte Carvalho Minighin ${ }^{\circ}{ }^{\circ}$, Lucas Vieira Silva ${ }^{2}{ }^{\circ}$, Carlos Antunes Oliveira de \\ Carvalho $^{5}$, Ana Carolina Gonçalves e Silva ${ }^{2}$, Luiz Edvaldo Teixeira ${ }^{4}$, Maria Juliete \\ Lucindo Rodrigues $^{2}{ }^{\circ}$, Thiago Batista Rodrigues Miranda ${ }^{5}$, Natália Nunes de Melo ${ }^{6} \bullet$ \\ ${ }^{2}$ Eng. Agr., Instituto Federal do Sudeste de Minas Gerais - Campus Barbacena, Barbacena-MG, Barbacena -MG, Brasil. \\ ${ }^{3}$ Méd. Vet., D. Sc., Professor do Instituto Federal do Sudeste de Minas Gerais-Campus Barbacena, Departamento de Zootecnia, Barbacena-MG, Brasil. \\ ${ }^{4}$ Gestor ambiental, Instituto Federal do Sudeste de Minas Gerais - Campus Barbacena, Barbacena - MG, Barbacena -MG, Brasil. \\ ${ }^{5}$ Graduando em Engenharia Agronômica pelo Instituto Federal do Sudeste de Minas Gerais -, Barbacena-MG, Barbacena-MG, Brasil. \\ ${ }^{6}$ Engenhieiro Agrônomo, Universidade Estadual de Santa Cruz-Itabuna-BA. \\ *Autor para correspondência, E-mail: queila.tavares13@hotmail.com
}

\begin{abstract}
Resumo. O processo de ensilagem de forragens é uma das principais formas de armazenamento, mantendo seu valor nutricional nos períodos de estiagem. Visando a melhora do processo fermentativo e eficiência na preservação das silagens, vem se utilizando inoculantes microbianos em muitas propriedades rurais. Desta forma, o presente estudo objetivou avaliar a qualidade nutricional das silagens de milho e de sorgo acrescida de doses de inoculante Silomax Milho e Sorgo (Lactobacillus plantarum) como aditivo em duas idades de corte. O experimento foi realizado no Núcleo de Agricultura do Instituto Federal do Sudeste de Minas - Campus Barbacena. O delineamento experimental foi inteiramente casualizado em esquema fatorial $2 \mathrm{X} 3$ com 5 repetições em silos de PVC (30 $\mathrm{cm}$ de comprimento e $100 \mathrm{~mm}$ de diâmetro) totalizando 30 silos para cada cultura. $\mathrm{O}$ inoculante foi aplicado nas seguintes doses: sem inoculante (apenas água); $100 \mathrm{~g}$ por tonelada e 200g por tonelada, os mesmos para cada idade de corte. Após 60 dias de ensilagem foram avaliados os níveis de Proteína Bruta (PB), Matéria Seca (MS), Fibra detergente neutro (FDN) e Fibra detergente ácido (FDA). Os resultados demonstraram que a silagem de sorgo foi significativamente influenciada em sua MS pelos tratamentos $(\mathrm{P}=$ $0,0081)$, não sendo observados efeitos entre as idades de corte $(P>0,05)$ com os teores de MS variando de 27,46 a 29,08\% na primeira idade de corte e de 29,17 a 29,66\% na segunda idade de corte. A utilização do inoculante bacteriano Lactobacillus plantarum teve efeito consistente apenas sobre os níveis de matéria seca da silagem de sorgo, não promovendo alterações significativas sobre as demais variáveis analisadas.
\end{abstract}

Palavras chave: bactérias; nutrição animal; volumosos.

\section{Nutritional evaluation of corn and sorgo silages inoculated with Lactobacillus plantarum}

Abstract. The forage silage process is one of the main forms of storage, maintaining its nutritional value during periods of drought. Aiming to improve the fermentation process and efficiency in the preservation of silages, microbial inoculants have been used in many rural properties. The objective of this study was to evaluate the nutritional quality of corn and sorghum silage plus doses of Silomax inoculant Corn and Sorghum (Lactobacillus plantarum) as additive at two cutting ages. The experiment was carried out at the Agricultural Center of the Federal Institute of Southeastern Minas - Campus Barbacena. 
The experimental design was completely randomized in a $2 \times 3$ factorial scheme with 5 replicates in PVC silos (30 cm long and $100 \mathrm{~mm}$ in diameter), totaling 30 silos for each crop. The inoculant was applied in the following doses: without inoculant (water only); 100 $\mathrm{g}$ per ton and $200 \mathrm{~g}$ per ton, the same for each cutting age. After 60 days of ensiling, the levels of crude protein (CP), dry matter (DM), neutral detergent fiber (NDF) and acid detergent fiber (FDA) were evaluated. The results showed that sorghum silage was significantly influenced in its DM by treatments $(\mathrm{P}=0.0081)$, and no effects were observed between the ages of cut ( $\mathrm{P}>0.05$ ) with DM ranging from 27.46 to $29.08 \%$ at the first cutting age and from 29.17 to $29.66 \%$ at the second cutting age. The use of the bacterial inoculant Lactobacillus plantarum had a consistent effect only on the dry matter levels of sorghum silage, not promoting significant changes on the other analyzed variables.

Keywords: Animal nutrition, Bacteria, Voluminous

\title{
Evaluación nutricional de maíz y silages de sorgo inoculados con Lactobacillus plantarum
}

\begin{abstract}
Resumen. El proceso de ensilaje forrajero es una de las principales formas de almacenamiento, manteniendo su valor nutricional durante los períodos de sequía. Con el objetivo de mejorar el proceso de fermentación y la eficiencia en la conservación de los ensilajes, se han utilizado inoculantes microbianos en muchas propiedades rurales. El objetivo de este estudio fue evaluar la calidad nutricional de los ensilajes de maíz y sorgo más las dosis de inoculante Silomax del maíz y sorgo (Lactobacillus plantarum) como aditivo en dos edades de corte. El experimento fue realizado en el Núcleo de Agricultura del Instituto Federal del Sureste de Minas - Campus Barbacena. El diseño experimental fue completamente aleatorio en un esquema factorial $2 \mathrm{X} 3$ con 5 repeticiones en silos de PVC (30 $\mathrm{cm}$ de largo y $100 \mathrm{~mm}$ de diámetro), con un total de 30 silos para cada cultivo. El inoculante se aplicó en las siguientes dosis: sin inoculante (solo agua); $100 \mathrm{~g}$ por tonelada y 200 g por tonelada, lo mismo para cada edad de corte. Después de 60 días de ensilado, se evaluaron los niveles de proteína cruda (CP), materia seca (MS), fibra detergente neutra (NDF) y fibra detergente ácida (FDA). Los resultados mostraron que el ensilaje de sorgo se vio significativamente influenciado en su $\mathrm{DM}$ por los tratamientos $(\mathrm{P}=0.0081)$, y no se observaron efectos entre las edades de corte $(\mathrm{P}>0.05)$ con DM que oscila entre 27.46 al $29,08 \%$ a la primera edad de corte y de 29,17 a $29,66 \%$ a la segunda edad de corte. El uso del inoculante bacteriano Lactobacillus plantarum tuvo un efecto constante solo en los niveles de materia seca del ensilaje de sorgo, no promoviendo cambios significativos en las otras variables analizadasl
\end{abstract}

Palabras clave: bacterias, nutrición animal, voluminoso

\section{Introdução}

A planta para se desenvolver e realizar fotossíntese precisam de níveis de energia solar, temperatura e umidade adequadas. Devido as mudanças de clima ao longo do ano de acordo com as estações climáticas há redução do crescimento vegetal resultando na falta de alimento para os animais à pasto no período de escassez de chuvas e luminosidade. Nesta época devido à falta de condições adequadas para a produção de alimentos as propriedades que utilizam sistemas de criação a pasto podem sofrer com a falta de alimento com isso necessitam de complementar a alimentação com outra fonte de volumoso (Von Pinho et al., 2007).

A produção de leite no Brasil em sua grande maioria baseia-se em sistemas de alimentação onde seus rebanhos são mantidos por meio de pastagens, isto devido a fatores econômicos e também para aproveitar a extensa diversidade de forrageiras tropicais (Perotto et al., 2010).

Entre as plantas para confecção de silagens, as mais usadas no mundo estão o milho (Zea mays) e o sorgo (Sorghum bicolor), devido os seus teores de carboidratos solúveis que contribui para a fermentação láctica no processo de ensilagem (Ferreira et al., 2001). 
De acordo com Fugita et al. (2012) e Santos et al. (2010) nos processos de conservação de ensilagem e fenação pode reduzir a qualidade dos alimentos causando alterações na composição química da forragem. Os microrganismos atrasam a fermentação causando a deterioração da forragem, agindo em competição com as bactérias ácido láticas por substrato diminuindo o valor nutricional gerando perdas no processo (Clark \& Ipharraguerre, 2001; Menezes et al., 2009; Neumann et al., 2007).

A utilização de aditivos microbianos na ensilagem contribui para a fermentação e conservação de nutrientes, tendo por objetivo a potencialização da fermentação direcionando os produtos após a abertura do silo à uma maior preservação de forragem (Andrade et al., 2010; Baliero Neto et al., 2009).

O presente trabalho objetivou analisar e comparar os efeitos dos inoculante microbiano Lactobacillus plantarum nas silagens de milho e sorgo em duas idades de corte.

\section{Material e métodos}

$\mathrm{O}$ experimento foi realizado no município de Barbacena, Minas Gerais (Latitude: $21^{\circ} 13^{\prime} 33^{\prime \prime} \mathrm{S}$, Longitude: $43^{\circ} 46^{\prime} 25^{\prime \prime} \mathrm{W}$ e altitude: 1164 metros), localizado na região da Serra da Mantiqueira, mesorregião do Campo das Vertentes nas dependências do Instituto Federal de Educação, Ciência e Tecnologia do Sudeste de Minas - Campus Barbacena (EMBRAPA).

A colheita e ensilagem foram realizadas em março de 2018, no Núcleo de Agricultura do Campus Barbacena. O milho foi colhido com colhedeira aos 105 e 110 dias na fase de maturação fisiológica do grão ( $28 \%$ e $32 \%$ de MS respectivamente) e processado em triturador picado em fragmentos médios de $2,5 \mathrm{~cm}$, de acordo com o manejo adotado.

A colheita do sorgo foi realizada aos 110 e 120 dias na fase de maturação fisiológica do grão (30\% e $35 \%$ de MS) com uma ensiladeira regulada para picagem em partículas de 2,5 cm de comprimento, quando os grãos da porção mediana das panículas se encontravam no estádio farináceo.

O inoculante foi adicionado nas silagens específicas após o processamento, de forma homogênea, por aspersão, de acordo com as recomendações do fabricante (100 g de inoculante para cada $50 \mathrm{t}$ de material, diluído em $100 \mathrm{~L}$ de água, ou seja $2 \mathrm{~L} / \mathrm{t}$ de material), não sendo adicionada água nas silagens controle, sendo o inoculante dissolvido em água destilada e sem cloro. O inoculante microbiano utilizado foi o Silomax ${ }^{\circledR}$ milho e sorgo, da Empresa Matsuda, composto por Lactobacillus plantarum.

O material processado foi ensilado em silos experimentais de PVC (30 cm de comprimento e 100 $\mathrm{mm}$ de diâmetro), com capacidade de aproximadamente $2,3 \mathrm{~kg}$. Os silos eram providos de válvulas, de forma a impedir a entrada de ar e permitir o livre escape dos gases da fermentação. Foram utilizados 5 silos laboratoriais por tratamento, com ou sem inoculante e para cada uma das idades de corte, totalizando 60 silos, sendo 30 para milho e 30 para sorgo (Tabela 1). Os silos foram mantidos no Laboratório Zootécnico no Núcleo de Zootecnia, em local à sombra e temperatura ambiente.

Tabela 1. Tratamentos e condições avaliadas no experimento

\begin{tabular}{lcc}
\hline \multirow{2}{*}{ Tratamentos } & \multicolumn{2}{c}{ Condições avaliadas } \\
\cline { 2 - 3 } & Milho, $1^{\circ}$ e $2^{\circ}$ corte & Sorgo $1^{\circ}$ e $2^{\circ}$ corte \\
\hline Tratamento 1: & Silagem controle & Silagem Controle \\
Tratamento 2: & $100 \mathrm{~g}$ para cada 50t & $100 \mathrm{~g}$ para cada 50t \\
Tratamento 3: & $200 \mathrm{~g}$ para cada 50t & $200 \mathrm{~g}$ para cada 50t \\
\hline
\end{tabular}

Para as silagens, a amostragem foi realizada aos 60 dias após a ensilagem. Na coleta das amostras, foram desprezados os primeiros cinco $\mathrm{cm}$ das porções superior e inferior dos silos, após esse procedimento, a silagem foi homogeneizada.

Após a retirada dos silos o material foi levado para secagem, foi acondicionado em saco de papel para secagem em estufa de ventilação forçada a $55^{\circ} \mathrm{C}$ por 72 horas, as amostras foram moídas em moinho de facas tipo Willey com peneira de $1 \mathrm{~mm}$ para determinação dos teores de Matéria Seca (MS), Proteína Bruta (PB) no qual seguiu-se a metodologia descrita pela (AOAC, 2005). Os teores de Fibra insolúvel em detergente neutro (FDN), Fibra insolúvel em detergente ácido (FDA) foram obtidos pelo método sequencial descrito por Robertson \& Van Soest (1981). 
As análises foram feitas no Laboratório de Química Analítica em Biossistemas (LAQBio) da Universidade Federal de São João Del Rei (UFSJ) e no Laboratório de Solos do IF Sudeste MG Campus Barbacena.

Foi utilizado um delineamento inteiramente casualizado em esquema fatorial (2:2:3) contento 30 parcelas experimentais para o milho e 30 para o sorgo igualmente divididas em 3 tratamentos ( 15 para cada idade de corte) utilizando o teste de Tukey, a 5\% de significância pela análise de variância ANOVA. As análises estatísticas foram realizadas pelo programa SISVAR 5.6 (Ferreira, 2011).

\section{Resultados e discussão}

Os valores de MS (Tabela 2) para as silagens de milho não foram influenciados pelos tratamentos e idades de corte $(\mathrm{P}>0,05)$ com valores de MS variando entre 26,8 e 28,3\% na primeira idade de corte e 27,3 a 27,6\% na segunda idade de corte. A silagem de sorgo (Tabela 3 ) teve seus valores de MS influenciada pelos tratamentos $(\mathrm{P}=0,0081)$, não sendo observados efeitos para as idades de corte $(\mathrm{P}>$ $0,05)$ com os teores de MS variando de 27,5 a $29,1 \%$ na primeira idade de corte a 29,2 a $29,7 \%$ na segunda idade de corte.

Tabela 2. Dados referentes aos teores médios de matéria seca (MS), proteína bruta (PB), fibra em detergente neutro (FDN) e fibra em detergente ácido (FDA), da silagem de milho, submetidas a diferentes doses do inoculante Silomax Milho e sorgo ${ }^{\circledR 2}$

\begin{tabular}{|c|c|c|c|c|c|c|c|c|}
\hline \multirow{2}{*}{ Tratamentos } & \multicolumn{2}{|c|}{ MS } & \multicolumn{2}{|c|}{ PB } & \multicolumn{2}{|c|}{ FDA } & \multicolumn{2}{|c|}{ FDN } \\
\hline & ID & ID2 & ID1 & ID2 & ID1 & ID2 & ID1 & ID2 \\
\hline Silagem controle & $26,77 \mathrm{aA}$ & $27,48 \mathrm{aA}$ & $9,33 \mathrm{aA}$ & $9,40 \mathrm{aA}$ & $28,45 \mathrm{aA}$ & $30,06 \mathrm{aA}$ & $59,31 \mathrm{aA}$ & $62,49 \mathrm{aA}$ \\
\hline $100 \mathrm{~g}$ para cada $50 \mathrm{t}$ & $28,10 \mathrm{aA}$ & $27,64 \mathrm{aA}$ & $9,02 \mathrm{aA}$ & $9,61 \mathrm{aA}$ & $30,32 \mathrm{aA}$ & $31,21 \mathrm{aA}$ & $57,15 \mathrm{aA}$ & $60,68 \mathrm{aA}$ \\
\hline $200 \mathrm{~g}$ para cada $50 \mathrm{t}$ & $28,33 \mathrm{aA}$ & $27,28 \mathrm{aA}$ & $8,88 \mathrm{aA}$ & $9,28 \mathrm{aA}$ & $33,79 \mathrm{aA}$ & $29,8 \mathrm{aA}$ & $60,04 \mathrm{aA}$ & $57,23 \mathrm{aA}$ \\
\hline \multicolumn{9}{|c|}{ P-valores } \\
\hline Tratamento & \multicolumn{2}{|c|}{0,5158} & \multicolumn{2}{|c|}{0,3932} & \multicolumn{2}{|c|}{0,4684} & \multicolumn{2}{|c|}{0,6773} \\
\hline ID & \multicolumn{2}{|c|}{0,2711} & \multicolumn{2}{|c|}{0,0536} & \multicolumn{2}{|c|}{0,7687} & \multicolumn{2}{|c|}{0,5723} \\
\hline Trat $\mathrm{x}$ ID & \multicolumn{2}{|c|}{0,2175} & \multicolumn{2}{|c|}{0,4906} & \multicolumn{2}{|c|}{0,3453} & \multicolumn{2}{|c|}{0,4506} \\
\hline
\end{tabular}

*Medias seguidas por letras minúsculas distintas na coluna e médias seguidas por letras maiúsculas distintas na linha são diferentes pelo teste de tukey a 5\% de significância ( $<<0,05)$. ID = Idade de corte $105 \mathrm{~d}$; ID = Idade de corte $110 \mathrm{~d}$.

Salvo et al. (2013) avaliando a composição nutricional de silagens de milho com cepas homo e heterofermentativas, avaliaram que as silagens com bactérias heterofermentativas quando comparada a silagem controle apresentaram redução no teor de MS, mostrando que ocorreram perdas sob forma de gases e efluentes no processo de fermentação heterolática que ocorreu pelo controle de microrganismos indesejáveis durante o processo fermentativo.

Tabela 3. Dados referentes aos teores médios de matéria seca (MS), proteína bruta (PB), fibra em detergente neutro (FDN) e fibra em detergente ácido (FDA), determinados das silagens de sorgo após o processo de ensilagem.

\begin{tabular}{lcccccccr}
\hline \multirow{2}{*}{ Tratamento } & \multicolumn{2}{c}{ MS } & \multicolumn{2}{c}{ PB } & \multicolumn{2}{c}{ FDA } & \multicolumn{2}{c}{ FDN } \\
\cline { 2 - 9 } & ID1 & ID2 & ID1 & ID2 & ID1 & ID2 & ID1 & ID2 \\
\hline Silagem controle & $27,46 \mathrm{aB}$ & $29,19 \mathrm{aA}$ & $6,35 \mathrm{aA}$ & $7,34 \mathrm{aA}$ & $37,77 \mathrm{aA}$ & $38,23 \mathrm{aA}$ & $59,94 \mathrm{aA}$ & $58,96 \mathrm{aA}$ \\
100 g para cada 50t & $28,68 \mathrm{aA}$ & $29,17 \mathrm{aA}$ & $6,60 \mathrm{aA}$ & $7,68 \mathrm{aA}$ & $36,53 \mathrm{aA}$ & $37,20 \mathrm{aA}$ & $57,57 \mathrm{aA}$ & $58,92 \mathrm{aA}$ \\
200g para cada 50t & $29,08 \mathrm{bA}$ & $29,66 \mathrm{bA}$ & $6,84 \mathrm{aA}$ & $6,61 \mathrm{aA}$ & $35,54 \mathrm{aA}$ & $36,86 \mathrm{aA}$ & $59,87 \mathrm{aA}$ & $56,37 \mathrm{aA}$ \\
\hline \multicolumn{7}{c}{ P- Valores } \\
\hline Tratamentos & 0,0081 & 0,1134 & & 0,2758 & 0,6141 \\
ID & 0,0458 & 0,6529 & 0,1522 & 0,8441 \\
Tratamento x ID & 0,2334 & 0,2941 & 0,8829 & 0,6313
\end{tabular}

*Medias seguidas por letras minúsculas distintas na coluna e médias seguidas por letras maiúsculas distintas na linha são diferentes pelo teste de tukey a 5\% de significância (P < 0,05). ID1 = Idade de corte $110 \mathrm{~d}$; ID2 = Idade de corte $120 \mathrm{~d}$.

Keles \& Demirci (2011) avaliaram o efeito do Lactobacillus plantarum em silagens de capim mombaça no qual verificaram que a adição do inoculante não trouxe diferenças na MS. Segundo Junges et al. (2013) as perdas de MS são ocasionadas pela fermentação, respiração celular e metabolismo de 
microrganismos anaeróbios, durante a ensilagem, com produção de água e $\mathrm{CO}_{2}$. Cavali et al. (2010) também não verificaram redução nas perdas de MS em silagens de capim-Elefante, inoculadas com bactérias homoláticas.

Segundo Oliveira et al. (2010) que avaliaram as silagens de milho, sorgo-sudão, sorgo forrageiro e girassol, e verificaram que as perdas em forma de gás variaram de 2,2 a $7,4 \%$ da MS. Schmidt et al. (2011) encontraram valores de perdas de 13,9\% da MS em silagens de cana-de-açúcar e Paziani et al. (2006), valores de 5,7 a 6,7\% da MS em silagens de capim-Tanzânia, com a umidade natural ou com recursos para elevar a MS.

Os teores de $\mathrm{PB}$ da silagem de milho (Tabela 2) não foram influenciados pelos tratamentos e pela idade de corte $(\mathrm{P}>0,05)$. Os teores de $\mathrm{PB}$ variaram de 8,9 a 9,3\% na primeira idade de corte e 9,3 a $9,6 \%$ na segunda idade de corte. Os teores de PB da silagem de sorgo (Tabela 3 ) não tiveram alterações pelos tratamentos e idades de corte $(\mathrm{P}>0,05)$. Os valores de $\mathrm{PB}$ variaram de $6,4 \%$ a $6,8 \%$ para a primeira idade de corte e para segunda idade de corte variaram entre $6,6 \%$ a $7,6 \%$.

Segundo Valadares Filho (2006), a concentração de proteína bruta na silagem de milho deve ser em torno de 7,3\%. Mizubuti et al. (2002) apontam valores da literatura variando de 4,6 a 9,5\% de PB chegando próximo aos valores encontrados no presente estudo em relação a silagem de milho.

De acordo com Rodrigues et al. (2014), ao avaliar inoculantes com bactérias heterofermentativas sobre a composição de silagens não obtiveram efeitos do inoculante bacteriano sobre os valores de PB, encontrando valores próximos ao do presente estudo, variando entre 9,3\% e 9,8\% comparando-se a silagem controle que foi de 9,4\%. Pedroso et al. (2000) avaliaram o uso de inoculantes em silagens de sorgo encontrando teores que variaram entre 7,9 e 8,3\% de MS; porém, não diferiu quanto ao teor de PB, em relação ao controle. Estes resultados confirmam os obtidos por Weinberg et al. (1993) ao avaliar o efeito da aplicação de inoculantes contendo L. plantarum, E. faecium e $P$. acidilactici sobre a composição nutricional e estabilidade aeróbica em silagens de sorgo, não obtendo diferenças significativas do efeito do inoculante nos teores de PB como no presente estudo.

Os níveis de Fibra insolúvel em detergente neutro (FDN), para as silagens de milho (Tabela 2) não foram influenciados pelos tratamentos e idades de corte $(\mathrm{P}>0,05)$ com valores de FDN variando entre $57,15 \%$ a $60,04 \%$ na primeira idade de corte e $57,23 \%$ a $62,49 \%$ na segunda idade de corte. Os teores de FDN da silagem de sorgo (Tabela 3 ) não foram afetados pelos tratamentos e idades de corte (P > 0,05 ) com valores de FDN variando entre $57,6 \%$ a $59,9 \%$ na primeira idade de corte e $56,4 \%$ a $59,0 \%$ para a segunda idade de corte. Segundo Neumann et al. (2017) a variável FDN é uma importante fonte de nutrientes para ruminantes, estimulando a ruminação e, consequentemente, a saúde do rúmen. Penteado et al. (2007) avaliando silagens de capim mombaça encontraram valores de 78,0\% de FDN e $40,6 \%$ de FDA. Ao adicionarem L. plantarum em doses crescentes nas silagens verificaram o aumento nos teores de FDA e FDN. Pesquisadores atribuem essa resposta ao aumento no consumo de substrato pelas bactérias adicionadas. Segundo estudo de Coan et al. (2005) não obteve alteração ao usarem bactérias homoláticas na ensilagem de capim-Mombaça, com teores médios de 75\% e 45,4\% de FDN e FDA, respectivamente. Kung et al. (2000) não observaram efeito da inoculação sobre os teores de FDN como no presente experimento. Rodrigues et al. (2014) relatam que o inoculante não teve efeito sobre a variável FDN não mudando em relação a silagem controle sendo o mesmo estudo com resultados próximos aos que consta nas tabelas 2 e $\underline{3}$.

A diminuição dos teores de carboidratos não estruturais ocasiona em um aumento dos teores de fibra, elevando também os componentes da matéria seca (Bernardes et al., 2008). Segundo McDonald et al, (1991) a hidrólise ácida da hemicelulose pode estar relacionada com a diminuição da FDN.

Os níveis de fibra insolúvel em detergente ácido (FDA), para as silagens de milho (Tabela 2) não foram influenciados pelos tratamentos e idades de corte $(\mathrm{P}>0,05)$ com valores variando entre $28,5 \%$ a $33,8 \%$ na primeira idade de corte e $29,8 \%$ a $31,2 \%$ na segunda idade de corte. Os teores de FDA da silagem de sorgo (Tabela 3), também não foram afetados pelos tratamentos e idades de corte $(\mathrm{P}>0,05)$ com valores de FDA variando entre $35,5 \%$ a $37,8 \%$ na primeira idade de corte e $36,9 \%$ a $38,2 \%$ para a segunda idade de corte. Segundo Neumann et al. (2017), os teores de FDA não devem ser elevados, pois a mesma é composta por lignina de porção indigestível, celulose parcialmente digestível e hemicelulose, que 
possui maior digestibilidade. De acordo com Silva \& Queiroz (2002), quando o FDA for menor, maior é o valor energético da silagem, resultando em um bom indicador de digestibilidade e valor energético.

Segundo os estudos de Wegbecher (2009) afirmaram que a ausência de resposta à adição de bactérias sobre as frações fibrosas da parede celular, pode indicar que o fornecimento de nutrientes do inoculante não proporcionou um crescimento na população de microrganismos que degradam fibra. Silva et al. (2005) constataram teores de FDA da silagem de sorgo não tratada e daquela tratada com o inoculante à base de Lactobacillus plantarum não foram influenciados pelo período de fermentação, apresentando, respectivamente, valores médios de 33,1 e 34,2\% de FDA.

Beleze et al. (2003) ao analisar silagens de milho verificou que o teor de FDA de 23,6\%, semelhante a Borreani \& Tabacco (2014) que encontraram silagens com 25,5\% de FDA, confirmando relatos de Silva et al. (2005) que encontraram resposta semelhante, com aumento da fração FDN, analisando que a adição de microrganismos à silagem não alterou a proporção de hemicelulose em silagens, porém o tempo de armazenamento diminuiu esse polissacarídeo.

Segundo Schmidt et al. (2011) há poucos estudos em relação a utilização de aditivos microbianos em silagens de sorgo, que pode ser explicado ao fato da silagem de sorgo ter um bom padrão fermentativo podendo-se dispensar a adição de bactérias no processo de ensilagem.

Segundo Jones et al. (1992), a resposta limitada das características finais do material ensilado à inoculação pode ser devida à quantidade de substrato insuficiente para o processo de fermentação. De acordo com Ely et al. (1982), a microbiota epifítica pode interferir no desempenho do inoculante, competindo pelo substrato.

Estudos sobre avaliação de aditivos microbianos com bactérias homofermentativas (Abdelhadi \& Tricarico, 2009; Lima et al., 2010; Vieira et al., 2004) e bactérias heterofermentativas (Thomas et al., 2013; Tabacco et al., 2011) verificaram que a adição de tais bactérias não melhoraram o processo fermentativo ou qualidade das silagens.

\section{Referências Bibliográficas}

Abdelhadi, L. O., \& Tricarico, J. M. (2009). Effects of stage of maturity and microbial inoculation at harvest on nutritive quality and degradability of grain sorghum whole-plant and head-chop silages. Animal Feed Science and Technology, 152(3-4), 175-185.

Andrade, I. V. O., Pires, A. J. V., Carvalho, G. G. P., Veloso, C. M., \& Bonomo, P. (2010). Perdas, características fermentativas e valor nutritivo da silagem de capim-elefante contendo subprodutos agrícolas. Revista Brasileira de Zootecnia, 39, 2578-2588.

AOAC. (2005). - Association Official Analytical Chemist. In A. O. A. Chemist (Ed.), Official Methods of Analysis (Official M). AOAC.

Baliero Neto, G., Ferrari Junior, E., Nogueira, J. R., Possenti, R., Paulino, V. T., \& Sartori, M. B. (2009). Perdas fermentativas, composição química, estabilidade aeróbia e digestibilidade aparente de silagem de cana-de-açúcar com aditivos químico e microbiano. Pesquisa Agropecuária Brasileira, 44(6), 621-630. https://doi.org/http://dx.doi.org/10.1590/S0100-204X2009000600011.

Baliero Neto, G., Siqueira, G. R., Nogueira, J. R., Reis, R. A., Roth, A. P. T. P., \& Roth, M. T. P. (2009). Perdas fermentativas e estabilidade aeróbia de silagens de cana-de-açúcar tratadas com cal virgem. Revista Brasileira de Saúde e Produção Animal, 10(1), 24-33. https://doi.org/http://dx.doi.org/10.1590/S0100-204X2009000600011.

Beleze, J. R. F., Zeoula, L. M., Cecato, U., Dian, P. H. M., Martins, E. N., \& Falcão, A. J. D. S. (2003). Evaluation of five corn hybrids (Zea mays, L.) at different maturity stages. 2. Structural component concentrations and correlations. Revista Brasileira de Zootecnia, 32(3), 538-545. http://www.scopus.com/inward/record.url?eid=2-s2.02342584743\& partnerID $=40 \& m d 5=b 8 c f e 8428 d 2 c 820 a 45887 c e 8 f 1 f 7 d f 87$

Bernardes, T. F., Reis, R. A., Amaral, R. C., Siqueira, G. R., Roth, A. P. P., Roth, M. de T. P., \& Berchielli, T. T. (2008). Perfil fermentativo, estabilidade aeróbia e valor nutritivo de silagens de capim-marandu ensilado com aditivos. Revista Brasileira de Zootecnia, 37(10), 1728-1736. 
Borreani, G., \& Tabacco, E. (2014). Improving corn silage quality in the top layer of farm bunker silos through the use of a next-generation barrier film with high impermeability to oxygen. Journal of Dairy Science, 97(4), 2415-2426. https://doi.org/http://dx.doi10.3168/jds.2013-7632.

Cavali, J., Pereira, O. G., Valadares Filho, S. C., Santos, E. M., Carvalho, G. G. P. de, Santos, M. V., Porto, M. O., \& Rodrigues, J. F. H. (2010). Bromatological and microbiological characteristics of sugarcane silages treated with calcium oxide. Revista Brasileira de Zootecnia, 39(7), 1398-1408. https://doi.org/http://dx.doi.org/10.1590/S1516-35982010000700002.

Clark, J. H., \& Ipharraguerre, I. R. (2001). Livestock Performance: Feeding Biotech Crops. Journal of Dairy Science, 84, Supple(0), E9-E18. https://doi.org/http://dx.doi.org/10.3168/jds.S00220302(01)70191-9

Coan, R. M., Vieira, P. de F., Silveira, R. N., Reis, R. A., Malheiros, E. B., \& Pedreira, M. S. (2005). Inoculante enzimático-bacteriano, composição química e parâmetros fermentativos das silagens dos capins Tanzânia e Mombaça. Revista Brasileira de Zootecnia, 34(2), 416-424.

Ely, L. O., Sudweeks, E. M., Moon, N. J. (1982). Chemical evaluation of Lactobacillus addition to alfalfa, corn, sorghum and wheat forage at ensiling. Journal of Dairy Science, v.65, n.4, p.1041-1046.

Ferreira, D. F. (2011). SISVAR: A Computer Statistical Analysis System. Ciência e Agrotecnologia, 35(6), 1039-1042. https://doi.org/http://dx.doi.org/10.1590/S1413-70542011000600001.

Ferreira, J. J., Cruz, J. C., Pereira Filho, J. A., \& Rodrigues, J. A. S. (2001). Estágio de maturação ideal para ensilagem do milho e do sorgo. In J. C. Cruz, I. A. Pereira Filho, J. A. S. Rorigues, \& J. J. Ferreira (Eds.), Produção e utilização de silagem de milho e sorgo (pp. 405-428). EMBRAPA.

Fugita, C. A., Prado, I. N., Jobim, C. C., Zawadzki, F., Valero, M. V., Pires, M. C. O., Prado, R. M., \& Françozo, M. C. (2012). Corn silage with and without enzyme-bacteria inoculants on performance, carcass characteristics and meat quality in feedlot finished crossbred bulls. Revista Brasileira de Zootecnia, 41(1). https://doi.org/10.1590/S1516-35982012000100023.

Jones, B. A., Hatfield, R. D., Muck, R. E. (1992). Effects of fermentation and bacterial inoculation on lucerne cell walls. Journal of Science Food Agriculture, v.60, n.2, p.147-155, 1992.

Junges, D., Schmidt, P., Novinski, C. O., \& Daniel, J. L. P. (2013). Additive containing homo and heterolactic bacteria on the fermentation quality of maize silage. Acta Scientiarum. Animal Sciences, 35(4), 371-377.

Keles, G., \& Demirci, U. (2011). The effect of homofermentative and heterofermentative lactic acid bacteria on conservation characteristics of baled triticale-Hungarian vetch silage and lamb performance. Animal Feed Science and Technology, 164(1-2), 21-28. https://doi.org/http://dx.doi.org/10.1016/j.anifeedsci.2010.11.017

Kung, L., Robinson Junior, R., Ranjit, N. K., Chen, J. H., Golt, C. M., \& Pesek, J. D. (2000). Microbial populations, fermentation end-products, and aerobic stability of corn silage treated with ammonia or a propionic acid-based preservative. Journal of Dairy Science, 83(7), 1479-1486.

Lima, R., Lourenço, M., Díaz, R. F. Castro, A., Fievez, V. (2010). Effect of combined ensiling of sorghum and soybean with or without molasses and lactobacilli on silage quality and in vitro rumen fermentation. Animal Feed and Silage Technology, v.155, p.122-131.

Mcdonald, P., Henderson, A. R. \& Heron, S. J. E. (1991). The biochemistry of silage. $2^{\text {nd }}$ ed. Marlow, Chalcombe.

Menezes, L. F. G., Segabinazzi, L. R., Brondani, I. L., Restle, J., Arboitte, M. Z., Kuss, F., Pacheco, P. S., \& Rosa, J. R. P. (2009). Silagem de milho e grão de sorgo como suplementos para vacas de descarte terminadas em pastagem cultivada de estação fria. Arquivo Brasileiro de Medicina Veterinária e Zootecnia, 61(1), 182-189. https://doi.org/10.1590/S0102-09352009000100026

Mizubuti, I. Y., Ribeiro, E. L. de A., Rocha, M. A., Silva, L. das D. F., Pinto, A. P., Fernandes, W. C., \& Rolim, M. A. (2002). Consumo e digestibilidade aparente das silagens de milho (Zea mays L.), sorgo (Sorghum bicolor (L.) Moench) e girassol (Helianthus annuus L.). Revista Brasileira de Zootecnia, 31(1), 267-272.

Neumann, M., Leão, G. F. M., Coelho, M. G., Figueira, D. N., Spada, C. A., \& Perussolo, L. F. (2017). Aspectos produtivos, nutricionais e bioeconômicos de híbridos de milho para produção de silagem. 
Archivos de Zootecnia, 66(253), 51-57.

Neumann, M., Mühlbach, P. R. F., Nörnberg, J. L., Ost, P. R., Restle, J., Sandini, I. E., \& Romano, M. A. (2007). Características da fermentação da silagem obtida em diferentes tipos de silos sob efeito do tamanho de partícula e da altura de colheita das plantas de milho. Ciência Rural, 37(3), 847-854. http://www.scopus.com/inward/record.url?eid=2-s2.034250020231\&partnerID=40\&md5=4335cb2a629a518afa4a0e67c632b903

Oliveira, L. B. de, Pires, A. J. V., Carvalho, G. G. P. de, Ribeiro, L. S. O., Almeida, V. V. de, \& Peixoto, C. A. de M. (2010). Perdas e valor nutritivo de silagens de milho, sorgo-sudão, sorgo forrageiro e girassol. Revista Brasileira de Zootecnia, 39(1), 61-67.

Paziani, S. F., Nussio, L. G., Loures, D. R. S., Igarasi, M. S., Pedroso, A. F., \& Mari, L. J. (2006). Influência do teor de matéria seca e do inoculante bacteriano nas características físicas e químicas da silagem de capim Tanzânia. Acta Scientiarum. Animal Sciences, 28(3), 265-271.

Pedroso, A. F., Freitas, A. R., \& Souza, G. B. (2000). Efeito de inoculante bacteriano sobre a qualidade da silagem e perda de matéria seca durante a ensilagem de sorgo. Revista Brasileira de Zootecnia, 29(1), 48-52.

Penteado, D. C. S., Santos, E. M., Carvalho, G. G. P., Oliveira, J. S., Zanine, A. M., Pereira, O. G. E., \& Ferreira, C. L. L. F. (2007). Inoculação com Lactobacillus plantarum da microbiota em silagem de capim-mombaça. Archivos de Zootecnia, 56(214), 191-202.

Perotto, D., Kroetz, I. A., \& Rocha, J. L. (2010). Milk production of crossbred Holstein $\times$ Zebu cows in the northeastern region of Paraná State. Revista Brasileira de Zootecnia, 39(4), 758-764. http://www.scopus.com/inward/record.url?eid=2-s2.077955448010\&partnerID $=40 \& m d 5=61 \mathrm{f} 52 \mathrm{f} 8 \mathrm{ff} 7528 \mathrm{cbd} 6 \mathrm{bc} 46 \mathrm{ce} 1 \mathrm{e} 70 \mathrm{~b} 22 \mathrm{ac}$

Robertson, J. B., \& Van Soest, P. J. (1981). The detergent system of analysis and its application to human foods. The Analysis of Dietary Fiber in Food, 3, 123.

Rodrigues, J. A. S., Tomich, T. R., Gonçalves, L. C., Albuquerque, C. J. B., GUIMARAES, A. de S., FERNANDES, L. de O., \& Paes, J. M. V. (2014). Sorgo forrageiro para silagem, corte e pastejo. Embrapa Milho e Sorgo, 35(278), 50-62.

Salvo, P. A. R., Basso, F. C., Rabelo, C. H. S., Oliveira, A. A., Sader, A. P., Casagrande, D. R., Berchielli, T. T., \& Reis, R. A. (2013). Características de silagens de milho inoculadas com Lactobacillus buchneri e L. plantarum. Archivos de Zootecnia, 62(239), 379-390.

Santos, G. T., Kazama, D. C. S., Kazama, R., \& Petit, H. V. (2010). Scientific progress in ruminant production in the 1 st decade of the XXI century. Revista Brasileira de Zootecnia, 39(SUPPL. 1), 478-490. https://doi.org/10.1590/S1516-35982010001300052

Schmidt, P., Rossi Junior, P., Junges, D., Dias, L. T., Almeida, R., \& Mari, L. J. (2011). Novos aditivos microbianos na ensilagem da cana-de-açúcar: composição bromatológica, perdas fermentativas, componentes voláteis e estabilidade aeróbia. Revista Brasileira de Zootecnia, 40(3), 543-549. https://doi.org/http://dx.doi.org/10.1590/S1516-35982011000300011.

Silva, A. V., Pereira, O. G., Garcia, R., Valadares Filho, S. C., Cecon, P. R., \& Ferreira, C. L. L. F. (2005). Composição bromatológica e digestibilidade in vitro da matéria seca de silagens de milho e sorgo tratadas com inoculantes microbianos. Revista Brasileira de Zootecnia, 34(6), 1881-1890.

Silva, D. J., \& Queiroz, A. C. (2002). Análise de alimentos: métodos químicos e biológicos (3rd ed.). Universdiade Federal de Viçosa.

Tabacco, E., Right, F., Quarantelli, A., Borreano, G. (2011). Dry matter and nutritional losses during aerobic deterioration of corn and sorghum silages as influenced by different lactic acid bacteria inocula. Journal of Dairy Science, v.94, p.1409-1419.

Thomas, M. E., Foster, J. L., Mccuistion, K. C., Redmon L. A., Jessup R. W. (2013). Nutritive value, fermentation characteristics, and in situ disappearance kinects of sorghum silage treated with inoculants. Journal of Dairy Science, v.96, p.7120- 7131, 2013.

Valadares Filho, S. C. (2006). Tabelas brasileiras de composição de alimentos para bovinos (Vol. 1). UFV.

Vieira, F. A. P., Borges, I., Stehling, C. A. V, Gonçalves, L. C., Coelho, S. G., Ferreira, M. I. C., \& 
Rodrigues, J. A. S. (2004). Qualidade de silagens de sorgo com aditivos. Arquivo Brasileiro de Medicina Veterinária e Zootecnia, 56(6), 764-772.

Von Pinho, R. G., Vasconcelos, R. C., Borges, I. D., \& Resende, A. V. (2007). Produtividade e qualidade da silagem de milho e sorgo em função da época de semeadura. Bragantia, 66(2), 235-245.

Wegbecher, F. X. (2009). Bactérias celulolíticas e o uso de resíduo de maracujá (Passiflora edulis) em rações extrusadas para juvenis de tambaqui (Colossoma macropomum): Vol. PhD. Instituto Nacional de Pesquisa da Amazônia.

Weinberg, Z. G., Ashbell, G., Hen, Y., \& Azrieli, A. (1993). The effect of applying lactic acid bacteria at ensiling on the aerobic stability of silages. Journal of Applied Bacteriology, 75(6), 512-518.

Recebido: 9 de setembro, 2019.

Aprovado: 1 de novembro, 2019.

Publicado: 24 de abril, 2020.

Licenciamento: Este artigo é publicado na modalidade Acesso Aberto sob a licença Creative Commons Atribuição 4.0 (CC-BY 4.0), a qual permite uso irrestrito, distribuição, reprodução em qualquer meio, desde que o autor e a fonte sejam devidamente creditados. 